\title{
HISTOPATHOLOGICAL ANALYSIS OF RENAL TUMOURS- A TWO YEAR STUDY FROM A TERTIARY CARE CENTRE
} \author{
Sheela Varghese ${ }^{6}$ \\ ${ }^{1}$ Assistant Surgeon, Kerala Health Services. \\ ${ }_{2}^{2}$ Additional Professor, Department of Pathology, Government Medical College, Kottayam, Kerala. \\ ${ }_{3}^{3}$ Senior Resident, Department of Pathology, Government Medical College, Kottayam, Kerala. \\ ${ }^{4}$ Additional Professor, Department of Pathology, Government Medical College, Kottayam, Kerala. \\ ${ }_{5}^{5}$ Assistant Professor, Department of Pathology, Government Medical College, Kottayam, Kerala. \\ ${ }^{6}$ Associate Professor, Department of Pathology, Government Medical College, Kottayam, Kerala.
}

Karthika Marath Chathukutty1, Lillykutty Pothen², Sangeetha Kandasamy³, Latha Vilasiniamma4, Jayalakshmi Payipat Leelamma5,

\begin{abstract}
BACKGROUND
ABSTRACT

There is an increased incidence of renal tumours every year in the last three decades, RCC being the most common. There is little published data on the spectrum of renal tumours in India, especially Southern parts like Kerala. Hence, this study is undertaken to analyse the relative frequencies of different types of renal tumours and their histopathological characteristics.

The aim of the study is to find out the mean age of presentation, mode of presentation and gender predominance of renal tumours, the histopathological subtype of renal tumours and microvascular invasion.
\end{abstract}

\section{MATERIALS AND METHODS}

This was a descriptive study carried out in the Department of Pathology, Government Medical College, Kottayam. 51 nephrectomy specimens of renal neoplasm received during the period of two years were studied. Statistical analysis was done using SPSS version 16.

\section{RESULTS}

Among 51 nephrectomy specimens of renal neoplasm, 90.2\% (46/51 cases) were of malignant tumours. Of 46 malignant cases $31 / 51$ cases were of clear cell carcinoma, 7/51 cases were of papillary carcinoma, 5/51 cases were of chromophobe carcinoma, 1/51 were of multilocular cystic RCC and 2/51 were of unclassified RCC. Of 5 benign cases (9.8\%) 2/51 were of oncocytoma, 1/51 were of solitary fibrous tumour, $1 / 51$ were of clear cell sarcoma and 1/51 were of angiomyolipoma. Majority of renal neoplasms $(90.2 \%)$ were RCC, seen predominantly in middle aged males (mean age is 52.41 years). They mostly presented with symptoms of abdominal pain (37.2\%) and mass (31.3\%). The classical symptom triad (macroscopic haematuria, palpable tumour and pain) was less commonly seen (8.7\%). Clear cell carcinoma was the most common histological type of renal tumours (60.7\%) and also had the most number of capsular (60\%) and renal sinus invasion (72\%), which may indicate bad prognosis. As the size, stage/ grade of the tumour increased, the symptoms did not increase. Therefore, relative paucity of symptoms does not mean that the tumour has not made much progression/ is completely curable/ resectable.

\section{CONCLUSION}

Incidental tumours being in the lower stages and lower nuclear grades indicate that early detection of renal neoplasms by radiological screening may have some value. However, large scale case control studies are needed to make accurate analysis of renal neoplasms including the measurement of cancer specific survival and prognosis.

\section{KEYWORDS}

Renal Tumours, Capsular Invasion, Vascular Invasion.

HOW TO CITE THIS ARTICLE: Chathukutty KM, Pothen L, Kandasamy S, et al. Histopathological analysis of renal tumours- a two year study from a tertiary care centre. J. Evolution Med. Dent. Sci. 2017;6(93):6712-6716, DOI: 10.14260/jemds/2017/1453

\section{BACKGROUND}

The incidence rates of RCC have risen steadily each year during the last three decades in most parts of the world with an average increase of $2 \%$ to $3 \%$ per year. $^{1}$ The increased incidence is primarily due to two reasons. One is the increased detection via radiological methods like USG and CT.

'Financial or Other Competing Interest': None.

Submission 24-10-2017, Peer Review 21-11-2017,

Acceptance 27-11-2017, Published 11-12-2017.

Corresponding Author:

Dr. Lillykutty Pothen,

Kaniankunnel House

Gandhinagar P. $O$,

Kottayam.

E-mail: glamskan@gmail.com

DOI: $10.14260 /$ jemds $/ 2017 / 1453$

\section{(c) $(i)(8)$}

Another reason is the increased prevalence of risk factors like obesity, smoking etc. ${ }^{1}$ In India, in the year 2010, there were an estimated 9333 incidences and 6049 mortalities due to kidney cancer. ${ }^{2} 30 \%-60 \%$ of renal tumours, particularly clinical stage T1 tumours are found incidentally in abdominal imaging performed for some other reason.2,3 Macroscopic haematuria, palpable tumour and pain together called the classic triad in RCC indicate metastatic disease.

${ }^{1}$ Radical/ partial nephrectomy is the gold standard treatment for renal tumours. Accurate and detailed histopathological examination of nephrectomy specimens of renal neoplasms is essential to establish histologic type and to assess prognostic determinants, i.e. tumour size, histological subtype, nuclear grade and stage. Therefore, this area offered an ideal research field. 


\section{Objective}

1. To find out the mean age of presentation, mode of presentation and gender predominance of renal tumours.

2. To study the histological study of renal tumours and microvascular invasion.

\section{MATERIALS AND METHODS}

This was a descriptive study done in the Department of Pathology, Government Medical College, Kottayam, Kerala. After obtaining Ethical Committee approval, 51 nephrectomy specimens of renal neoplasms which were received in the department for a period of two years were analysed. Nephrectomies done for non-neoplastic conditions were excluded in this study. Nephrectomies were done in the Department of Urology of the same institution and were sent in a formalin filled container. The clinical details of 51 nephrectomy cases were collected by reviewing the medical records. All specimens were processed routinely for $\mathrm{H}$ and $\mathrm{E}$. After examining the $\mathrm{H}$ and $\mathrm{E}$ slides, histological typing of renal tumours was done according to WHO classification of Renal Tumours, 2016. Capsular/ vascular/ renal sinus invasion were assessed. Appropriate staging and nuclear grading are done based on AJCC $8^{\text {th }}$ edition of the TNM classification of RCC and Fuhrman grading. Statistical analysis was done using SPSS version 16 .

\section{RESULTS}

\section{Case Distribution}

Of 51 nephrectomy specimens, 46/51 was RCC; 5/51 were others which include solitary fibrous tumour, clear cell sarcoma, angiomyolipoma and oncocytoma.

\section{Histological Typing of Renal Tumours}

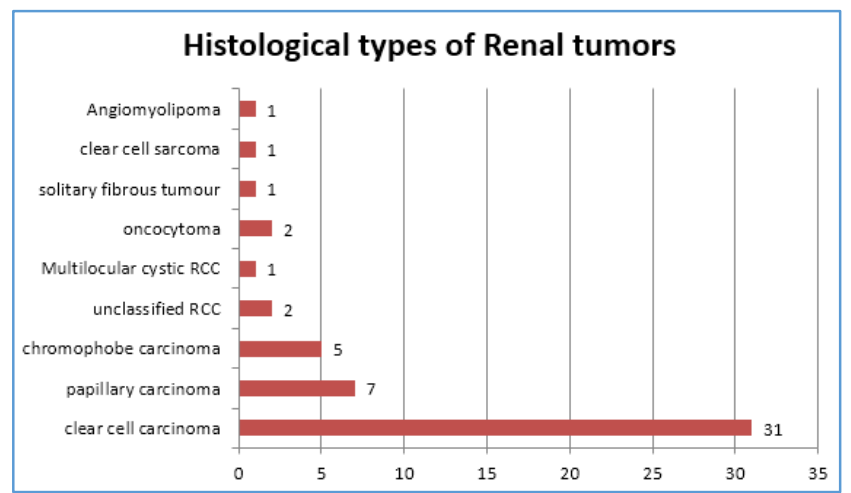

Graph 1. Histological Typing of Renal Tumours

Hence, the most common histological type of renal tumour in this study was clear cell carcinoma, which constitutes $60.7 \%$.

\section{Age of Presentation}

In the present study, most of the patients $(31.3 \%$; 16$)$ were in the age group of 51 to 60 years followed by $27.4 \%$ (15) were in the age group of 41 to 50 years. Minimum age of the study population was 4 years and maximum age was 74 years with a mean age of 52.41 years.

\section{Mode of Presentation}

In this study, the most common clinical symptom (37.2\%; 19 patients) was abdominal/ flank pain followed by abdominal mass in 16 patients $(31.3 \%)$.

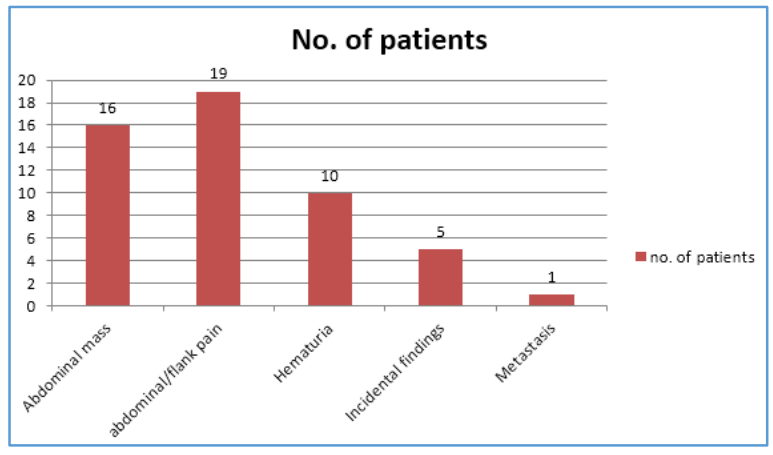

Graph 2. Mode of Presentation

There were five incidentally found renal tumours in the present study. All of them were RCC, three being clear cell carcinoma and one each of papillary carcinoma and chromophobe carcinoma.

\section{Gender Predominance}

Male: Female ratio $=35$ (68.6\%): 16 (31.4\%)

Hence, the number of males were almost double of that of females.

Histological Type and Vascular, Capsular and Renal Sinus Invasion

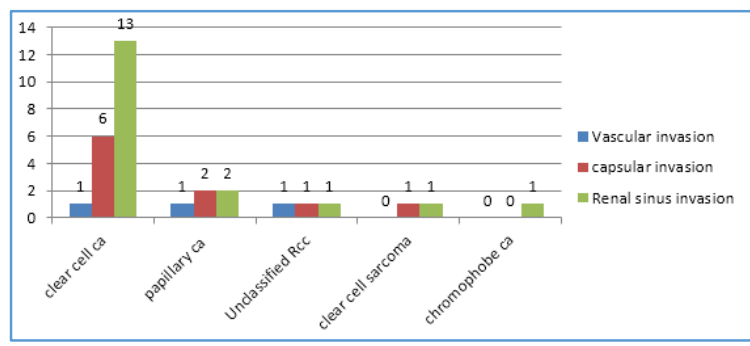

Graph 3. Histological Type and Vascular, Capsular and Renal Sinus Invasion

Clear cell carcinoma had the highest incidence of capsular $(60 \%)-6 / 20$ cases and renal sinus invasion of $(72 \%)-13 / 20$ cases.

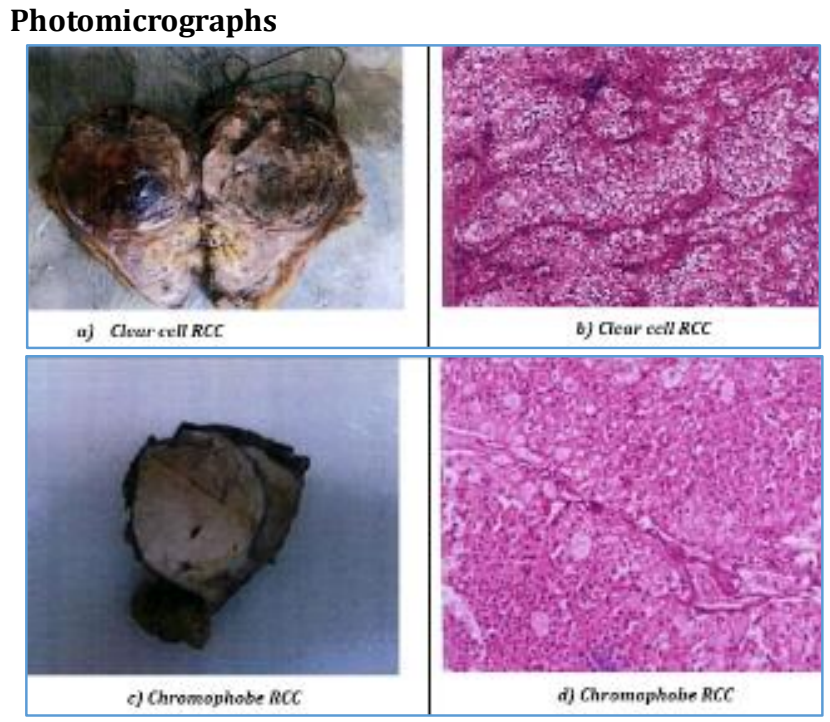

Figure 1. Clear Cell RCC ( $a$ and $b$ ) and Chromophobe RCC (c and d) 


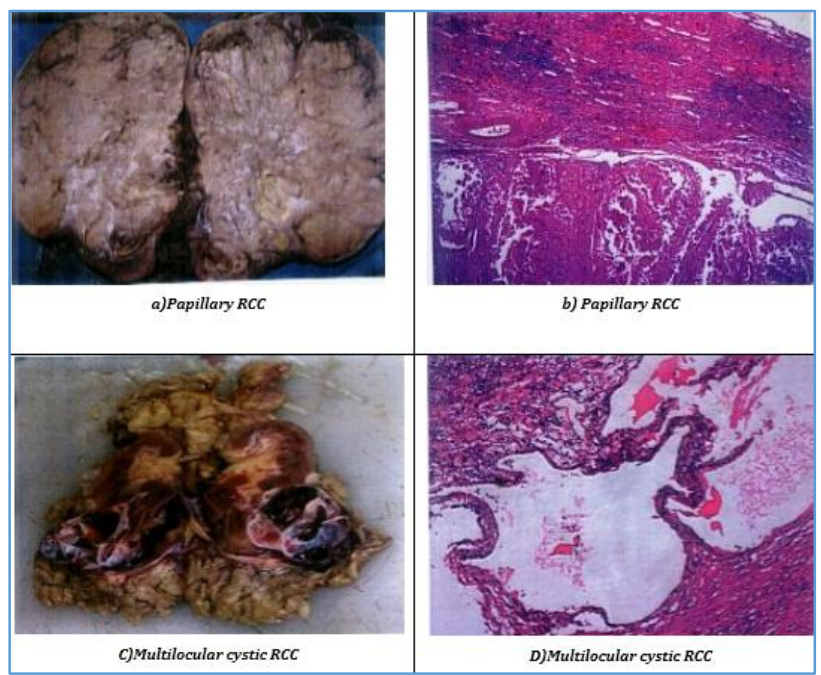

Figure 2. Papillary RCC ( $a$ and b) and Multilocular Cystic RCC (c and d)



c) Angiomyolipoma

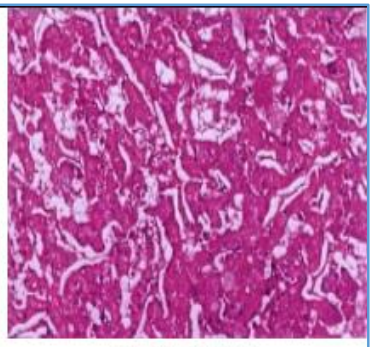

b) Oncocytoma

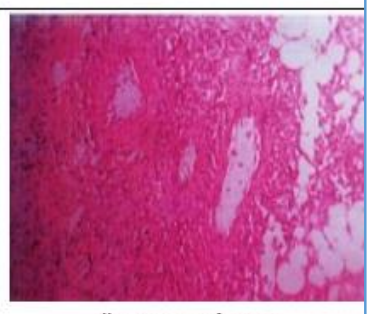

d) Angiomyolipoma
Figure 3. Oncocytoma (a and b) and Angiomyolipoma (c and d)

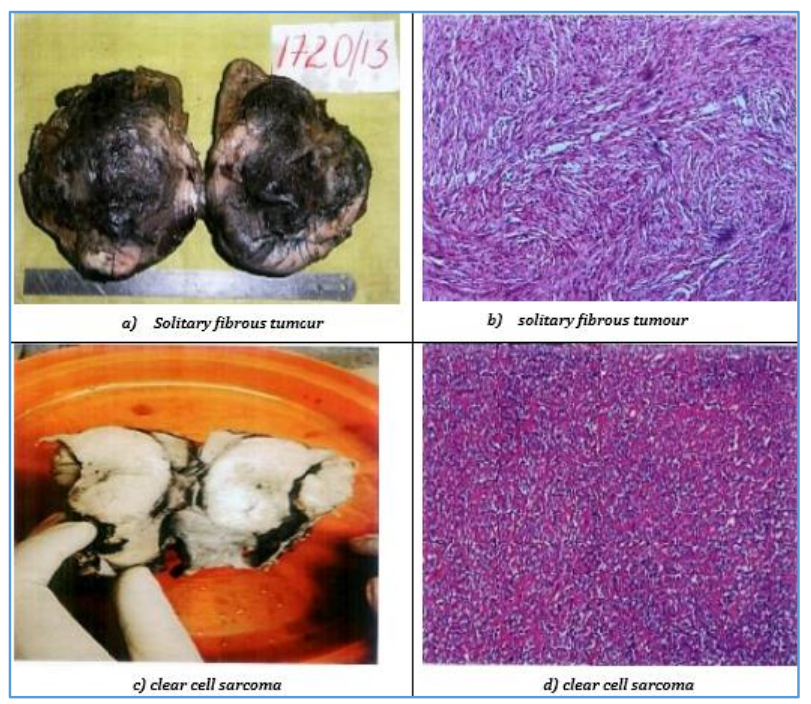

Figure 4. Solitary Fibrous Tumour ( $a$ and $b$ ) and Clear Cell Sarcoma (c and d)

\section{DISCUSSION}

The incidence of renal tumours, particularly renal cell carcinoma is increasing worldwide. ${ }^{1}$ These tumours will have variable presentation patterns. An accurate clinical analysis and histological typing has become vital in deciding the treatment modalities and survival of these patients. 4

51 nephrectomy specimens were studied, of these 47 specimens were malignant tumours $(92.15 \%)$. This is in accordance with Frank et al study, ${ }^{5}$ which includes 2770 adult patients who underwent radical nephrectomy or nephronsparing surgery for sporadic unilateral non-metastatic solid renal tumours. In Frank et al study, 87.2\% cases were RCC.

The age wise distribution showed that most of the patients in this study were in the age group of 51 to 60 years, which comprised $31.3 \%$ (16) of the study population followed by $27.4 \%$ (15) in the age group of 41 to 50 years, which is similar to the results obtained by Badmus et al 6 and Aghaji et al,7 who showed the peak incidence to be in the age group of 45 - 60 years.

Minimum age of the study group was 4 years and maximum age was 74 years with a mean age of 52.41 years. Tabibi et $\mathrm{al}^{8}$ showed mean age was 55.3 years. Gudbjartsson et al $^{9}$ and Renshaw et al $^{10}$ showed similar mean age values ranging from 52 to 68.3 years.

In this study, most of the patients were males, $68.6 \%$ (i.e. 35 cases), almost double the number of females who accounted for $31.4 \%$ (i.e. 16 cases). This male gender predominance is also seen in various other studies.7,8

Thus, renal neoplasms are predominantly a disease of the middle-aged patients, most often males. Renal cell carcinoma is the frequent type of tumour. Mode of presentation of renal tumours ( $90 \%$ of them being RCC) were variable in our study with the most common clinical symptom in renal neoplasm being abdominal/ flank pain, reported by 19 patients (37.2\%), followed by abdominal mass in 16 patients (31.3\%). The patients having RCC, presenting with haematuria were only 10 , i.e. $21.7 \%$ which is in contrast to previously published literature and study by Masuda et al ${ }^{11}$ which showed haematuria to be as high as $40 \%$. Our findings of abdominal pain and mass being the commonest symptoms are comparable to the results obtained by Badmus et $\mathrm{al}^{6}$ and Mbaeri et al.12

The clinical triad of haematuria, flank pain and abdominal mass of RCC were present in 4 out of 46 cases of RCC, i.e. 8.7\%. Similar results are published by Porena et $\mathrm{al}^{13}$ and Masuda et al,11 and they also found that the occurrence of the triad indicated poor prognosis. There were 5 incidentally found renal tumours in the studied specimens, i.e. tumours accidentally detected when radiological evaluation was done for some non-renal pathology.

\section{Histopathological Analysis}

Grossly, 5 the tumours had extensive necrosis. ${ }^{3}$ Clear cell carcinoma had sarcomatoid differentiation. Necrosis and sarcomatoid differentiation are indicative of poor prognosis. ${ }^{14}$ Histologic categorisation of renal epithelial neoplasms showed patterns similar to the contemporary classification scheme. Histological subtyping is important in the prognosis of renal cell carcinoma. Various studies demonstrate that there are significant differences in outcome for different histologic subtypes of RCC, highlighting the need for accurate subtyping. 15 
The most common histopathological type of renal tumour in the present study was clear cell carcinoma, comprising 31 cases $(60.7 \%)$. Isah et $\mathrm{al}^{16}(61.5 \%)$ and Sascha et al ${ }^{17}(77.9 \%)$ also showed the predominant cell type to be clear cell carcinoma. The second commonest one was papillary carcinoma followed by chromophobe carcinoma, just as the pattern in previous studies.

The most common histopathological type of renal tumour in both males and females in this study was clear cell carcinoma, $25(71.4 \%)$ and $6(37.5 \%)$ cases respectively. Clear cell carcinoma was the commonest histopathological type of renal tumour in the age group less than or equal to 40 , $41-50,51-60$ and $61-70$. These findings also tally with the ones in the literature.16,17

\section{Microvascular Invasion}

Microvascular invasion is an important prognosticator in high risk cases for the development of metastatic disease when demonstrated. Capsular invasion may serve as an additional factor in high-risk stratification of patients with localised RCC. ${ }^{18}$ RCC invading the renal sinus are more likely to have higher nuclear grade, regional lymph node involvement and sarcomatoid transformation than tumours invading only the perinephric fat. ${ }^{19}$ These patients therefore deserve closer follow-up and perhaps adjuvant therapy.

In our study one case each (33.3\%) of clear cell carcinoma, papillary carcinoma and RCC unclassified had displayed renal vein invasion. Clear cell carcinoma had the most incidence of capsular invasion, 6 cases in total (60\%) and renal sinus invasion in 13 of them (72\%). A study by Bonsib et $\mathrm{al}^{20}$ also showed clear cell carcinoma to be the commonest cell type invading renal sinus (42\%). The followup and analysis of survival was not the objective of our study.

\section{Incidental Tumours}

There were 5 incidentally detected tumours in this study, all of them being RCC. There were 3 cases of clear cell carcinoma and 1 case each of papillary carcinoma and chromophobe carcinoma. Thus, $10.87 \%$ of RCC in this study group were found incidentally. The incidence of incidental RCC has been studied in a number of retrospective series as well as population surveys, and it ranged from $15 \%$ to $61 \% .21,22$

The association between tumour sizes of incidental and symptomatic RCC were also analysed in this study. There were no statistically significant tumour size difference between incidentally found RCC and those which produced symptoms.

In the present study, the incidentally detected RCC were having low stages ( 1 and 2 ) and lower nuclear grades ( 1 and 2). In a study by Luciani et al, ${ }^{23}$ a study of 1092 RCC patients, a lower stage $(74 \%$ versus $49.1 \%)$ and nuclear grade $(75.5 \%$ versus $56.9 \%$ ) were registered in the incidentally found neoplasms than in the symptomatic neoplasms.

\section{CONCLUSION}

Majority of renal neoplasms were malignant (92.15\%). The most common malignant renal neoplasm was renal cell carcinoma (90\%). Majority of the patients were males (68.6\%), i.e. M: F ratio being > 2: 1 . Most patients belong to the age group of $41-60$ years. The mean age of the patients was 52.41 years. Most common presenting symptoms with renal tumours were abdominal pain $(37.2 \%)$ and abdominal mass (31.3\%). One of the commonly described symptoms, haematuria was less frequent in this study. The occurrence of classical symptom triad of RCC- haematuria, flank pain and abdominal mass was also low $(8.7 \%)$ in this study.

$10.87 \%$ of renal tumours were incidentally detected. The most common histopathological type of renal tumour in this study was clear cell carcinoma $(60.7 \%)$ and it was also the most common type in males and in females.

Clear cell carcinoma was the commonest histopathological type of renal tumours in the age group less than 40, 41 - 50, 51 - 60 and 61 - 70. Clear cell carcinoma had the highest incidence of capsular $(60 \%)$ and renal sinus invasion $(72 \%)$. There was no correlation between increased symptoms and tumour size, stage or nuclear grade. There was no correlation between tumour size among incidental and symptomatic RCCs. The incidental RCC in this study were in the lower stage (1 and 2) and lower nuclear grade (1 and 2). Incidental tumours being in the lower stages and lower nuclear grade indicate that early detection of renal neoplasms by radiological screening may have some value.

However, large scale case control studies are needed to make accurate analysis of renal neoplasms including the measurement of cancer specific survival and prognosis.

\section{REFERENCES}

[1] Ferlay J, Shin HR, Bray F, et al. Estimates of worldwide burden of cancer in 2008: GLOBOCAN 2008. Int J Cancer 2010;127(12):2893-917.

[2] Jemal A, Siegel R, Xu J, et al. Cancer statistics, 2010. CA Cancer J Clin 2010;60(5):277-300.

[3] Smith SJ, Bosniak MA, Megibow AJ, et al. Renal cell carcinoma: earlier discovery and increased detection. Radilogy 1989;170(3 Pt 1):699-703.

[4] Ljungberg B, Cowan NC, Hanbury DC, et al. EAU guidelines on renal cell carcinoma: the 2010 update. Eur Urol 2010;58(3):398-406.

[5] Frank I, Blute ML, Cheville JC, et al. Solid renal tumours: an analysis of pathological features related to tumour size. J Urol 2003;170(6 Pt 1):2217-20.

[6] Badmus TA, Salako AA, Arogundade FA, et al. Malignant renal tumours in adults: a ten year review in a Nigerian hospital. Saudi J Kidney Dis Transpl 2008;19(1):120-6.

[7] Aghaji AE, Odoemene CA. Renal cell carcinoma in Enugu, Nigeria. West Afr J Med 2000;19(4):254-8.

[8] Tabibi A, Parvin M, Abdi H, et al. Correlation between size of renal cell carcinoma and its grade, stage, and histological subtype. Urol J 2007;4(1):10-3.

[9] Gudbjartsson T, Hardarson S, Petursdottir V, et al. Histological subtyping and nuclear grading of renal cell carcinoma and their implications for survival: a retrospective nation-wide study of 629 patients. Eur Urol 2005;48(4):593-600.

[10] Renshaw AA. Subclassification of renal cell neoplasms: an update for the practising pathologist. Histopathology 2002;41(4):283-300.

[11] Masuda H, Kurita Y, Nakanishi T, et al. Can symptoms predict the prognosis of renal cell carcinoma? A multivariate analysis of 320 patients. International Journal of Clinical Oncology 1997;2(1):6-9. 
[12] Mbaeri TU, Orakwe JC, Nwofor AM, et al. Malignant renal tumours in Nnamdi Azikiwe university teaching hospital, Nnewi, Nigeria. Niger J Med 2012;21(4):37780.

[13] Porena M, Vespasiani G, Rosi $P$, et al. Incidentally detected renal cell carcinoma: role of ultrasonography. J Clin Ultrasound 1992;20(6):395-400.

[14] Cheville JC, Lohse CM, Zincke H, et al. Sarcomatoid renal cell carcinoma: an examination of underlying histologic subtype and an analysis of associations with patient outcome. Am J Surg Path 2004;28(4):435-41.

[15] Amin MB, Amin MB, Tamboli P, et al. Prognostic impact of histologic subtyping of adult renal epithelial neoplasms: an experience of 405 cases. Am J Surg Pathol 2002;26(3):281-91.

[16] Isah RT, Sahabi SM, Adamu SN, et al. Histopathological pattern of renal tumours seen in Usmanu Danfodiyo University teaching hospital Sokoto, Nigeria. African Journal of Cellular Pathology 2013;1:9-13.

[17] Pahernik S, Ziegler S, Roos F, et al. Small renal tumors: correlation of clinical and pathological features with tumor size. J Urol 2007;178(2):414-7.
[18] Song T, Yin Y, Liao B, et al. Capsular invasion in renal cell carcinoma: a meta-analysis. Urol Oncol 2013;31(7):1321-6.

[19] Ornellas AA, Andrade DM, Ornellas P, et al. Prognostic factors in renal cell carcinoma: analysis of 227 patients treated at the Brazilian national cancer institute. Int Braz J Urol 2012;38(2):185-94.

[20] Bonsib SM, Gibson D, Mhoon M, et al. Renal sinus involvement in renal cell carcinomas. Am J Surg Pathol 2000;24(3):451-8.

[21] Gudbjartsson T, Einarsson GV, Magnusson J. A population based analysis of survival and incidental diagnosing of renal cell carcinoma patients in Iceland, 1971-1990. Scand J Urol Nephrol 1996;30(6):451-5.

[22] Sweeney JP, Thornhill JA, Grainger R, et al. Incidentally detected renal cell carcinoma: pathological features, survival trends and implications for treatment. $\mathrm{Br} \mathrm{J}$ Urol 1996;78(3):351-3.

[23] Luciani LG, Cestari R, Tallarigo C. Incidental renal cell carcinoma-age and stage characterization and clinical implications: study of 1092 patients (1982-1997). Urology 2000;56(1):58-62. 